\title{
Proceeding
}

Supplementary Issue: Spring Conferences of Sports Science. International Conference on Psychology of Education Sciences \& Lifestyle.

\section{The impact of programmed e-learning of the tactical aspects on the level of tactical thinking and decision- making for basketball course students}

\author{
MAJED SALEEM EL-SALEH \\ College of Education, Humanities and Social Sciences, Al Ain University, United Arab Emirates
}

\begin{abstract}
This study aimed to identify the impact of programmed e-learning of the tactical aspects on the level of tactical thinking and decision-making among students of the basketball course, where the sample of the study consisted of (50) students from the Department of Physical Education and Sports Science at the University of Taibah, from those who have completed the requirements of team sports course (1) (basketball), and enrolled in the second semester of the academic year 2016/2017, and the study was conducted using a single group design, where a program of programmed tactical aspects was applied to the sample. In order to achieve the objectives of the study, the researcher used the experimental approach as it suits the nature of this study. After using the appropriate statistical treatments, the results of the study showed that the programmed e-learning of the tactical aspects had a positive effect on the sample members. The results showed that there was a statistically significant effect on their level of tactical thinking and decision making when comparing the results of the pre and post measurements of the sample members. In the light of the results of the study, the researcher recommended the use of The Tactical Thinking Scale in the case of enrolling students in the team sports, basketball course (1). The study also recommended conducting studies on the program of tactical thinking in addition to some psychological and social qualities such as "emotional stability, achievement motivation, and mental perception, leadership" and similar studies on other practical courses.

Keywords: Physical education; E-Learning; Tactical aspects; Tactical thinking; Decision making; Basketball.
\end{abstract}

\section{Cite this article as:}

El-Saleh, M.S. (2020). The impact of programmed e-learning of the tactical aspects on the level of tactical thinking and decision-making for basketball course students. Journal of Human Sport and Exercise, 15(3proc), S922-S937. doi:https://doi.org/10.14198/jhse.2020.15.Proc3.44

Corresponding author. College of Education, Humanities and Social Sciences, Al Ain University, United Arab Emirates.

E-mail: majed.elsaleh@aau.ac.ae

Supplementary Issue: Spring Conferences of Sports Science. International Conference on Psychology of Education Sciences and Lifestyle.

JOURNAL OF HUMAN SPORT \& EXERCISE ISSN 1988-5202

(c) Faculty of Education. University of Alicante

doi:10.14198/jhse.2020.15.Proc3.44 


\section{INTRODUCTION}

The sports training process seeks to achieve the best sporting levels so as to work to raise the level of players to the maximum extent possible, by taking advantage of all the players abilities, whether those capabilities physical, skill, mental, tactical, psychological and applied through training units and competition.

Tactical aspects are one of the most important things to keep in mind to improve the players' abilities and improve their performance levels.

Tactical thinking is one of the most important requirements of competitive sports performance with a set of elements, there is a strong positive relationship between the tactical preparation, and physical and skill preparation, as tactical preparation depends heavily on comprehensive preparation because the player cannot carry out the tasks assigned to him without high physical, skills and psychological ability.

The observer of the game of modern basketball believes that it is characterized by speed in all its skill, including the large number of tactical movements performed by players in the games, whether these moves individually or collectively, defensive or offensive. In an attempt to achieve the maximum points and win the games, the importance of the tactical preparation is shown as one of the main pillars that form the (sports form) for the players and the speed of deciding their decisive decisions, as indicated by Shaalan and Abu Majd (1996), and Abu Alia 2007.

Al Jabali (2003) points out that tactical thinking is one of the most important requirements of competitive sports performance, as thinking processes play an important role in an individual's activities and responses while practicing different aspects of sports activities when implementing a plan, this is due to his appreciation of the position or perception of a relationship related to the course of play and the appropriate decisionmaking, as referred to by (Holt \& Sparkes (2001, Hayek and Khaldi (2006) and Al-Qaraan (2003) and Hawari (2011) in their study of decision-making in the field of sports activities when implementing a plan.

Tactical learning aims to make an individual acquires abilities in planning, information and tactics, and how to master them enough to be able to choose well and act in multiple play situations that always change during competition, this is what was indicated to by Abdul-Mohsen (2003), Al-Ahdal Study (2006), Al-Faqih (2008), and Abu Alia (2007), in the tactical thinking of football and basketball players.

Whereas Ali's study (2005) came about Fencing game. Tactical learning is based on motor learning, as plans are a set of motor skills implemented in a coordinated and skilled manner.

\section{STUDY PROBLEM}

There is a widening gap between developed and developing countries in the field of teaching methods through traditional fields that are making efforts to catch up with this advanced civilization. And this will not come in the absence of the use of contemporary technology in education in general and software in particular, Barell (1991).

The primary goal of any competition is to always win, and win will only be achieved through an attackingthought, keeping in mind the goal of the attack as well as the level of tactical thinking and decisions-making by the players, Which is one of the most important aspects that researchers and trainers seek to promote in the game of basketball through educational and training programs, and this is what has been seen by the 
researcher in studies and scientific research related to the subject of the study. These include the study of Khion (2008) and Al- Qaraan (2003), the study of Mahmoud (2005), the study of Haniyeh (2006), and the study of Dulaimi (2006) Morris (1996).

Where the problem of the study lies - from the researcher's experience in the field of basketball in terms of education, training and arbitration- that there is a weakness in the offensive and defensive planning performance of students who completed the course of basketball, team sports (1), both individually and collectively level, the researcher sees through his work as a faculty member in the department, where he interviewed a number of teachers and supervisors of basketball at the University of Taibah, who all stressed that what is taught in the course of basketball and team sports (1) is the basic skills Of the game without giving the planning aspects adequate attention. Therefore, this drew the attention of the researcher to do this study to identify the impact of programmed e- learning of the tactical aspects of basketball on the level of tactical thinking and decision - making among students of the Department of Physical Education at the University of Taibah.

\section{Study importance}

Learning the tactical thinking requires the ability to change his behaviour and adjust it according to the changing playing positions during the competition to quickly recall the experiences of previous situations experienced. Hence the importance and speed of decision-making based on the facts on the ground and previous experiences that help the player to take the decision taking into account the general interest of the team (Shaalan and Abu Majd, 1996).

The importance of this study lies in its endeavour to contribute to improving the quality of educational and learning output by keeping abreast of the latest technological developments in this era. And work to introduce the technology of education (programmed) as one of the most important means of assistance in the educational and training system, especially in the field of tactical thinking and decision-making among basketball students. This study contributes to the transfer of the impact of learning in competitive situations during different sports games. Also, the importance of this study lies in emphasizing the importance of tactical training as it is one of the cornerstones to form the training situation and the sportive form, for students and basketball players.

It also seeks to find a program to develop the skills of tactical thinking can be applied to players on the one hand and students of departments and faculties of physical education in universities on the other. And helping basketball specialists in finding ways to train players in tactical thinking and decision-making, as well as making sure that the computer can be used to develop tactical thinking by simulating some elements of play situations and developing the ability of players to make the right decision at the right time in different playing situations. This study is one of the very few studies - within the limits of the researcher's knowledge - that dealt with the introduction of programmed education for the planning aspects in basketball specifically and at the level of tactical thinking and decision-making among universities students in general, and at Taibah University in particular, and non-participants in sports clubs.

\section{Study objectives}

This study aimed to identify:

1. The impact of programmed e-learning of the planning aspects of basketball on the level of tactical thinking among students of the course of basketball and team sports (1) at the University of Taibah.

2. The Effect of programmed E-Learning for planning aspects in Basketball on the level of decisionmaking skills for students of basketball and team sports courses (1) at Taibah University. 
3. Develop an educational program that includes programmed planning aspects that can be included in the vocabulary of basketball and team sports (1) at Taibah University.

\section{Study hypotheses}

This study put forward the following hypotheses:

1. Are there statistically significant differences at the level of significance $(\alpha \leq .05)$ between the preand post-measurements among the sample members in the level of tactical thinking?

2. Are there significant differences at the level of significance $(\alpha \leq .05)$ between the pre- and postmeasurements among the respondents in the decision-making skill level?

\section{Study determinants}

The study was limited to students of the Department of Physical Education and Sports Sciences at the University of Taibah from the non- participants in the clubs and university teams.

Spatial Element:

Indoor Hall / Taibah University - Madinah / Saudi Arabia.

Time Element:

The second semester of the academic year 2016/2017 from (12/2/2017 to 14/5/2017). The present study includes (35) playing positions for (6) weeks with (3) meetings per week.

The human Element:

Students who have completed the course of team sports basketball (1) Department of Physical Education and Sports Science at the University of Taibah and non-participants in the teams of clubs and the university and enrolled in the second semester (50) students.

\section{Study procedures}

The study approach

The researcher used the experimental method, one group design, because it suits the nature of this study.

The study population

The study population consisted of students of the Department of Physical Education and Sports Science at Taibah University who completed the course of team sports basketball (1) and enrolled in the second semester of the academic year 2016/2017.

The study sample

The sample of the study consisted of (50) students of the Department of Physical Education and Sports Sciences at Taibah University who completed the course of basketball, team sports (1), who were selected randomly. The following is a presentation of the arithmetic average and standard deviations of the study sample.

Table 1. Arithmetic averages and standard deviations of the study sample.

\begin{tabular}{lcc}
\hline Variable & Arithmetic Average & Standard Deviation \\
\hline Age & 20.3 & 1.82 \\
Length & 1.73 & 7.89 \\
Weight & 64.00 & 4.41 \\
\hline
\end{tabular}




\section{Study tools}

Planning aspects program

The researcher designed the programmed electronic tutorial based on the use of multimedia technology using the computer (Video Clips of Basketball Drills - Basics, Coach's Clipboard) after using the design of both Hayek and Al-Dmoor (2011) and adapt them to the game's basketball plans. Several specialized studies and references in this field were reviewed, including: Al-Saleh (2011) Shaalan and Abu Al-Majd (1997), Mohammadi and Ali (1998), Ali (2005), Nassif (2006), Abu Alia (2007), and Faqih (2008). Where the program included (35 playing position) drawn and explained in sequence according to the movements of the players (Appendix No.1), and shows the movements of team members in the attack, and the way to present the situation to students using a computer, the sample members then applied this in the stadium, where the individuals are distributed in the position and the application is carried by each individual in the same position to all sites so that everyone can know the importance of each movement in the position, the program was applied for six weeks at a rate of (3) times a week, and (60) minutes per unit of study.

Then, the educational program of tactical thinking was applied for (6) weeks, with (3) units of instruction per week as shown in Table 2 for the application from (14/2/2018 to 16/5/2018). The application of the existing tactical positions in the program was approved based on the following distribution:

\section{The survey experience}

A survey study was applied on a sample (rationing sample) and consisted of (8) players from the study population, then were randomly selected and later excluded from the study sample. The aim of the 8-day survey was to ascertain how the study procedures were coordinated and when they were to be carried out. As well as the application of measurement methods and know their suitability and identify obstacles that may face the researcher and the assistant team in the application and record tests and observations.

\section{Steps of conducting the study}

Procedures of application

1. The sample of the study was met in the first unit on 12/2/2018, where the decision-making scale and the tactical thinking scale were distributed to conduct pre-tests and data collection.

2. The unit of instruction lasted 60 minutes, divided into the theoretical part by using a computer slide show for 15 minutes, and the practical part which included the performance of what the program presented for 45 minutes.

3. After that, the post-tests were applied on 16/4/2018.

Table 2. Plan of implementation of planning aspects program.

\begin{tabular}{lll}
\hline Week Number & Unit Number & Position number (figure) \\
\hline Week One & First & $1+2$ \\
& Second & $3+4$ \\
& Third & $5+6$ \\
\hline Week Two & Fourth & $7+8$ \\
& Fifth & $9+10$ \\
& Sixth & $11+12$ \\
\hline Week Three & Seventh & $13+14$ \\
& Eighth & $15+16$ \\
& Ninth & $17+18$ \\
\hline Week Four & Tenth & $19+20$ \\
& Eleventh & $21+22$ \\
\hline
\end{tabular}




\begin{tabular}{lll} 
& Twelfth & $23+24$ \\
\hline Week Five & Thirteenth & $25+26$ \\
& Fourteenth & $27+28$ \\
& Fifteenth & $29+30$ \\
\hline Week Six & Sixteenth & $31+32$ \\
& Seventeenth & $33+34$ \\
& Eighteenth & 35 \\
\hline
\end{tabular}

\section{Tactical thinking scale}

The Tactical Thinking Scale is designed to be consistent with the objectives of the study by modifying several studies scales in this field. These include the Hayek and Dhamour study (2011), which used the study of Abu Alia (2007), Mohammadi and Ali (1998), and Nassif (2006), where these references were used in building and designing the scale and the introduction of basketball plans on it (Appendix 2).

\section{Decision-making scale}

The researcher used the decision-making scale of Hayek and Dhamour (2011), which consists of (24), paragraphs (Appendix No. 4 \& 3 ).

1. Pre-tests: The researcher conducted pre-tests of the members of the study sample in the tactical thinking and skills and decision-making before the application of the program.

2. Post-tests: The researcher conducted the post-tests of the sample of the study after the application of the programmed educational program in tactical thinking, with note that the scale of tactical thinking was used in the same way for the pre- and post-tests.

\section{Scientific parameters of instruments}

Parameters of veracity of the decision-making and tactical thinking scales:

The researcher relied on the sincerity of the content achieved by the Hayek and Dhamour study (2011), by presenting the scale to arbitrators from the specialists, and the scale has settled in its final form after making the necessary adjustments and stability on the final form of the two measures on (24) paragraph, and (16) different educational position.

\section{Stability of two studies measures}

The researcher relied on the percentage of stability achieved by the measures of the two study of Hayek and Dhamour (2011), Where the stability rate of the method of application of the test and Re- test (Test - Re Test) on a survey sample, relatively high and reached (.846), which is acceptable for such types of studies, and Table 3 shows that.

Table 3. Stability results of the tactical aspect evaluation tool by the testing and re-application method.

\begin{tabular}{llllrl}
\hline \multicolumn{2}{l}{ First application } & \multicolumn{2}{l}{ Second application } & Correlation & \multicolumn{2}{l}{$\begin{array}{l}\text { Significance } \\
\text { Level }\end{array}$} \\
\hline Arithmetic & Standard & Arithmetic & Standard & Coefficient & \\
Average & Deviation & Average & Deviation & & .003 \\
\hline 1.78 & 0.61 & 1.93 & 0.53 & .846 & .003 \\
\hline
\end{tabular}

Table 3 shows the results of the stability of the planning aspect tool by the method of applying testing and re-application. The value of the correlation coefficient between the two applications was (.846) at a level of significance (.003), a statistically significant value and expresses an acceptable and appropriate level of stability of the planning aspect scale. 
Table 4. The results of the stability of the decision-making scale by internal consistency in Alpha-Cronbach method.

Overall Average of decision making Number of Paragraphs 24 Alpha Cronbach value .923

Table 4 shows the results of the stability of the decision-making scale by the internal consistency in the AlphaCronbach method. The value of alpha Cronbach for the tool was (.923), which is appropriate and sufficient for the purposes of this study, because it refers to the values of internal consistency to a high degree.

\section{Statistical processing}

Arithmetic averages, standard deviations, and T-test were used to collect the necessary data using statistical processors.

\section{DISCUSSION AND PRESENTATION OF RESULTS}

\section{Presentation of the results related to the first hypothesis}

Are there statistically significant differences at the level of significance $(\alpha \leq .05)$ between the pre- and postmeasurements among the sample members in the level of tactical thinking?

Table 5. Arithmetic averages and standard deviations for each form of the Tactical Thinking Scale in the preand post-measurements of the sample members, the value of $T$ and the significance level.

\begin{tabular}{|c|c|c|c|c|c|c|}
\hline \multirow{2}{*}{$\begin{array}{l}\text { Test } \\
\text { Form Number }\end{array}$} & \multicolumn{2}{|c|}{ Before } & \multicolumn{2}{|c|}{ After } & \multirow[t]{2}{*}{$\begin{array}{l}\mathrm{T} \\
\text { Value }\end{array}$} & $\begin{array}{l}\text { Significance } \\
\text { level }\end{array}$ \\
\hline & $\begin{array}{l}\text { Arithmetic } \\
\text { Mean }\end{array}$ & $\begin{array}{l}\text { Standard } \\
\text { Deviation }\end{array}$ & $\begin{array}{l}\text { Arithmetic } \\
\text { Mean }\end{array}$ & $\begin{array}{l}\text { Standard } \\
\text { Deviation }\end{array}$ & & \\
\hline Form 1 & 1.4 & 0.7 & 2.6 & 0.52 & & \\
\hline Form 2 & 1.1 & 0.32 & 2.8 & 0.42 & & \\
\hline Form 3 & 1.05 & 0 & 2.4 & 0.7 & & \\
\hline Form 4 & 1 & 0 & 2.5 & 0.71 & & \\
\hline Form 5 & 1.1 & 0.32 & 2.5 & 0.71 & & \\
\hline Form 6 & 1.4 & 0.7 & 2.4 & 0.7 & & \\
\hline Form 7 & 1 & 0 & 2.6 & 0.52 & & \\
\hline Form 8 & 1.3 & 0.67 & 2.6 & 0.7 & & \\
\hline Form 9 & 1.1 & 0.32 & 2.3 & 0.67 & 31.86 & .000 \\
\hline Form 10 & 1.05 & 0 & 2.8 & 0.84 & & \\
\hline Form 11 & 1 & 0 & 2.7 & 0.48 & & \\
\hline Form 12 & 1.3 & 0.32 & 2.6 & 0.52 & & \\
\hline Form 13 & 1.05 & 0 & 2.4 & 0.7 & & \\
\hline Form 14 & 1.1 & 0.32 & 2.2 & 0.92 & & \\
\hline Form 15 & 1 & 0 & 2.6 & 0.84 & & \\
\hline Form 16 & 1.3 & 0.67 & 2.5 & 0.53 & & \\
\hline $\begin{array}{l}\text { Scale as a Whole } \\
\text { for the Tactical } \\
\text { Side }\end{array}$ & 1.14 & 0.09 & 2.53 & 0.12 & & \\
\hline
\end{tabular}

Table 5 shows the arithmetic averages and standard deviations for each form of the tactical Thinking Scale in the pre- and post-scales. It also shows the overall average of the forms for the pre- and post-scales of the 
sample members. The table showed that the sample members obtained a total average (1.14) and a standard deviation of $(0.09)$ in the pre-measurement. The table also shows that the sample members obtained a total average (2.53) and a standard deviation of $(0.12)$ in the post-measurement. Observing the values of the total averages in Table 5 , it was observed that the sample members in the post-measurement obtained the highest overall average, which means a high level of tactical thinking among the sample members after the application of the program.

Table 5 shows the value of $(T)$ calculated between the pre- and post-measurement averages in the tactical side of the sample members. The value of $(T)$ calculated (31.86) at a level of significance (.000) where we find that the value of the level of significance was less than the value (.05), which indicates the existence of statistically significant differences between the pre and post measurements, so that this significance was in favour of the telemetry with the best arithmetic average, which was (2.37).

The results of this study were in agreement with the study of Hayek and Dmoor (2011), Al-Ahdal (2006) and Nassif (2006), that the level of tactical thinking has increased as a result of practicing the program used, and the researcher attributes this development to the content of the program in many of the planning aspects, where it is natural to provide students with a lot of information and skills and multiple planning and varied varying degrees of difficulty and diversity. In addition to developing the ability of players in imagination and mental perception in addition to linking similar play situations in training on the ground in the play and the use of intelligence of the player with the experience of the plans learned from the program, he will notice a significant improvement in how these tactical attitudes are addressed and implemented to the fullest. This is also consistent with the study of Waqqad (2003), Bishtawi and Khawaja (2005) and Mahmoud (2008), Hayek and Khaldi (2006).

Where Hayek and Dmoor pointed out (2011), citing Faqih (2008), "that training programs work to raise the level of planning behaviour, where programs are working to develop the ability to think fast and effective to assess the situation of the plan, It also develops thinking, the ability to distribute the attention, the reaction speed and the ability to realize the distance and the proper timing of playing the ball.

\section{Presentation of the results related to the second hypothesis}

Are there statistically significant differences at the level of significance $(\alpha \leq .05)$ between the pre- and postmeasurements among the sample members in the level of decision-making skill?

Table 6. Arithmetic averages and standard deviations for each paragraph of the decision-making scale in the pre- and post-measurements of the sample members, the value of $(T)$ and the significance level.

\begin{tabular}{|l|l|c|c|c|c|c|c|}
\hline \multirow{2}{*}{ No. } & Paragraphs & \multicolumn{2}{|c|}{ Before } & \multicolumn{2}{|c|}{ After } & T & Significance \\
\cline { 2 - 6 } 1 & $\begin{array}{c}\text { Arithmetic } \\
\text { Average }\end{array}$ & $\begin{array}{c}\text { Standard } \\
\text { Deviation }\end{array}$ & $\begin{array}{c}\text { Arithmetic } \\
\text { Average }\end{array}$ & $\begin{array}{l}\text { Standard } \\
\text { Deviation }\end{array}$ & $\begin{array}{l}\text { value } \\
\text { level }\end{array}$ \\
\hline & $\begin{array}{l}\text { I have no difficulty in } \\
\text { pinpointing play } \\
\text { positions accurately }\end{array}$ & 3.3 & 0.95 & 3.2 & 1.7 & & \\
\hline & $\begin{array}{l}\text { When I encounter a } \\
\text { game situation, I } \\
\text { retrieve information } \\
\text { where I can pinpoint } \\
\text { solutions. }\end{array}$ & 3.5 & 1.18 & 4.8 & 0.42 & 000 \\
\hline
\end{tabular}




\begin{tabular}{|c|c|c|c|c|c|}
\hline 3 & $\begin{array}{l}\text { I put alternatives to } \\
\text { the playing positions } \\
\text { facing me. }\end{array}$ & 2.3 & 1.16 & 4.7 & 0.48 \\
\hline 4 & $\begin{array}{l}\text { I feel a sense of } \\
\text { anxiety when making } \\
\text { decisions while } \\
\text { playing }\end{array}$ & 1.9 & 1.2 & 4.7 & 0.48 \\
\hline 5 & $\begin{array}{l}\text { When I face new } \\
\text { game positions, I } \\
\text { choose the first } \\
\text { solution I can find }\end{array}$ & 2.75 & 1.45 & 4.8 & 0.42 \\
\hline 6 & $\begin{array}{l}\text { I try to predict all the } \\
\text { consequences of } \\
\text { making a decision. }\end{array}$ & 2.9 & 0.99 & 4.9 & 0.32 \\
\hline 7 & $\begin{array}{l}\text { When I make a } \\
\text { decision, I try to make } \\
\text { it satisfactory to my } \\
\text { team }\end{array}$ & 2.3 & 0.82 & 4.5 & 0.53 \\
\hline 8 & $\begin{array}{l}\text { When the first } \\
\text { solution to the } \\
\text { situation fails, I feel } \\
\text { unable to deal with } \\
\text { different situations }\end{array}$ & 2.5 & 0.91 & 4.9 & 0.32 \\
\hline 9 & $\begin{array}{l}\text { The most challenging } \\
\text { situations I play are } \\
\text { difficult, and I can } \\
\text { solve them. }\end{array}$ & 3.3 & 1.25 & 5 & 0 \\
\hline 10 & $\begin{array}{l}\text { I expect the best } \\
\text { results when a } \\
\text { decision is made on } \\
\text { the playing position. }\end{array}$ & 3.1 & 1.29 & 4.5 & 0.97 \\
\hline 11 & $\begin{array}{l}\text { When I decide on a } \\
\text { play position, I } \\
\text { compare the } \\
\text { consequences of my } \\
\text { decision with those } \\
\text { expected before the } \\
\text { decision. }\end{array}$ & 3.8 & 1.23 & 4.9 & 0.72 \\
\hline 12 & $\begin{array}{l}\text { Look for other } \\
\text { alternatives if the first } \\
\text { alternative fails to } \\
\text { take advantage of the } \\
\text { playing position. }\end{array}$ & 2.5 & 1.58 & 5 & 1.25 \\
\hline 13 & $\begin{array}{l}\text { Always look for the } \\
\text { most successful }\end{array}$ & 3.3 & 1.06 & 4.6 & 0.52 \\
\hline
\end{tabular}




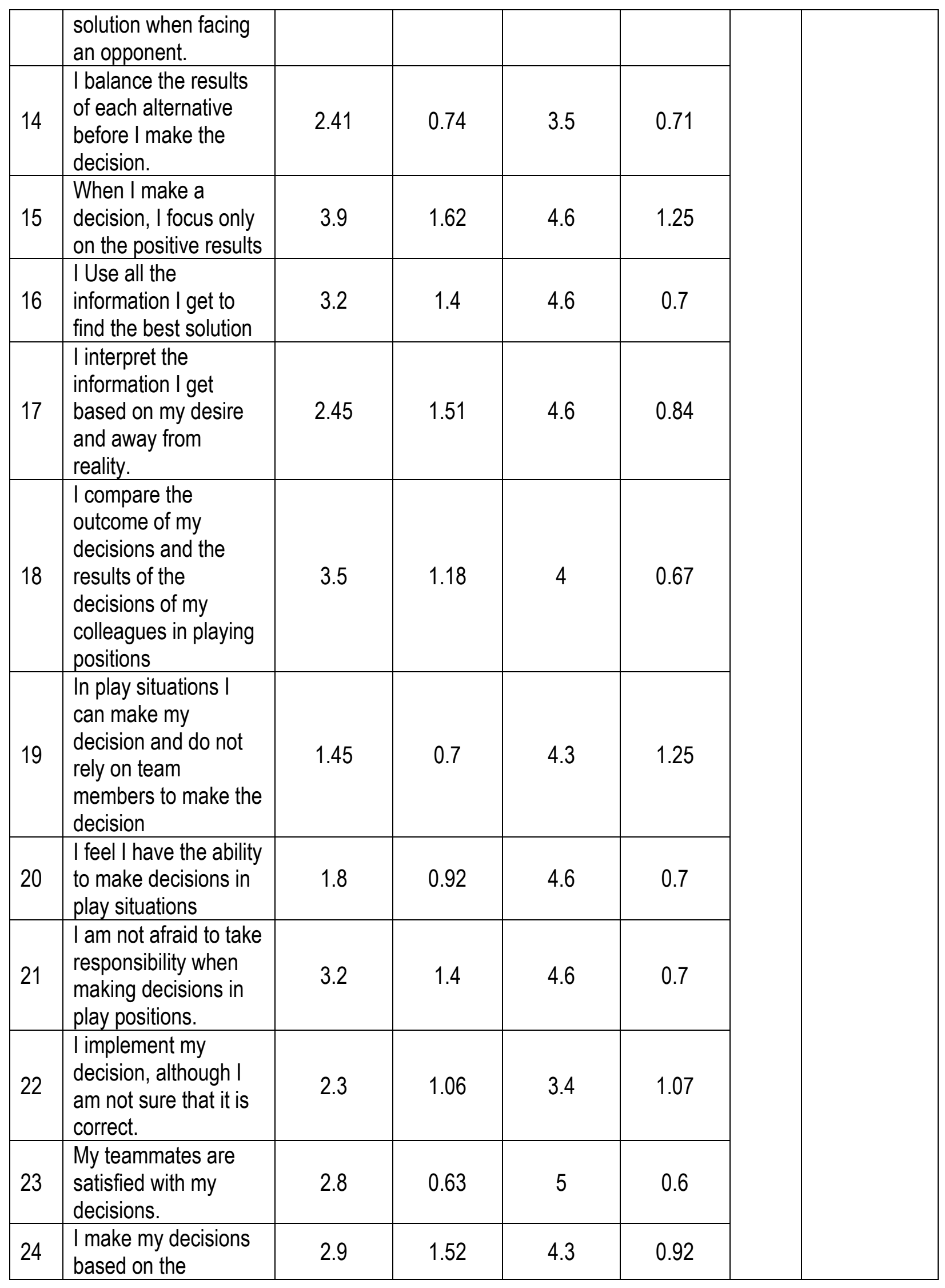




\begin{tabular}{|l|l|l|l|l|l|l|l|}
\hline $\begin{array}{l}\text { positions of my } \\
\text { colleagues on the } \\
\text { stadium }\end{array}$ & & & & & \\
\hline Total decision- making & 2.80 & 0.69 & 4.50 & 0.28 & & \\
\hline
\end{tabular}

Table 6 shows the arithmetic averages and standard deviations for each paragraph of the decision-making scale in the pre- and post-measurements. It also shows the overall average of paragraphs in the two measurement scales of the sample members. The sample showed a total average (2.80) and a standard deviation of (0.69) in the pre-measurement. The table also shows that the sample members, in the postmeasurement obtained a total average (4.50) and a standard deviation of (0.28). By observing the values of the total averages in Table 6, it was observed that the sample members in the post-measurement obtained the highest total average. Where the value of $(T)$ calculated between the averages of pre and post measurement in decision-making among the sample members, and the value of (T) calculated (6.48) at a level of significance $(.000)$ we find that the value of the level of significance was less than the value $(.05)$. This indicates that there are statistically significant differences between the pre and post measurements so that this sign was in favour of the post-measurement with the best arithmetic average which was (4.50).

The researcher attributes this development in the level of decision-making to the outcome of the experiences gained through the implementation of the programmed electronic program, where the levels of students were close when performing pre-tests, whether on the tactical thinking scale or decision-making scale and the reason that they are students and non-practicing players in clubs, while their levels have risen after the implementation of the plan aspects program, and this was a proof of effectiveness of the program to improve decision-making, and that educational or training programs of the planning aspects help in the development of decision-making process, especially if individuals are alerted to focus on everything going on around them during play situations, and solving problems that students face in difficult situations.

This is what Zghoul (2009) pointed out in the decision-making process as a mental skill that can be developed in individuals. The individual can be trained on how to make decisions through training in problem solving, planning and setting goals. The individual can also be trained in imagination, freedom of thought, and the generation of alternatives through brainstorming techniques. Although it is difficult to reach a rational decision completely, it is possible to reach the most appropriate decision for a particular situation.

And that the player who has the ability to observe and then think properly must be followed by making the right decision according to the educational position. The results of this study are consistent with those of Mohammadi and Ali (1998), Hamida (2005) (2001), Holt \& Sparkes and Mokhtar (1985), (1995 Turner \& Martinek, and Qaraan (2003). The results of this study are consistent with the studies of Mohammadi and Ali (1998), Hamida (2005) (2001), Holt \& Sparkes and Mokhtar (1985), (1995 Turner \& Martinek, and Qaraan (2003), which agreed on the evolution of the level of decision-making skill of the members of the experimental samples whether in studies that have been in the field of sports or in the educational field in general.

\section{CONCLUSIONS}

In light of the presentation and discussion of the results, the researcher concluded the following:

1. The possibility of developing the level of tactical thinking and decision-making skills as a result of programmed and electronic educational programs for students of different levels and specializations.

2. The possibility of using programmed education using computer technology to teach the planning aspects of basketball. 
3. Decision-making, from the mental processes that need to be strengthened and developed, is most important in the process of tactical thinking.

4. The development of tactical thinking is inextricably linked with appropriate decision-making in multiple and diverse play situations.

\section{RECOMMENDATIONS}

In the light of the above conclusions, the researcher recommends:

1. Apply the programmed electronic program to the sample of the players of the university teams and clubs.

2. Adopt the Tactical Thinking Scale in order to evaluate the students enrolled in the team sports (1) basketball and similar in the faculties and departments of physical education.

3. Applying study tools (the program and tactical thinking scale) at different levels of study and categories.

4. Conducting a study that includes a program of planning aspects, skills and psychosocial qualities such as "emotional stability, achievement motivation, mental perception, leadership" to find out its effect on tactical thinking.

Making similar studies on other practical courses in colleges and departments of physical education.

\section{REFERENCES}

Abdul Mohsen (2003) the effectiveness of the use of some psychological skills "relaxation - mental perception - focus attention" in raising the level of skill and planning performance of football players. Unpublished Master Thesis, Egypt: Helwan University.

Abdullah, Heba. (2008). The Effect of Using Two Calculated Multimedia Strategies on the Ability to Solve Sportive Problems and Creative Thinking of Basic Stage Students in UNRWA Schools in Northern Amman, MA Thesis (Unpublished), University of Jordan, Amman, Jordan.

Abu Abdu, Hassan Al-Sayed (2001). Modern Trends in Football Planning and Training, Alexandria, Egypt: Al-Isha'a Al-Fanny Printing Press and Library.

Abu Alia, Mutasim (2007), Tactical thinking among basketball players in Jordan, Master Thesis (unpublished), Yarmouk University, Irbid, Jordan.

Abu Salem and Wafika Mustafa (2007). Application of Educational Technology and Activation of the Educational Learning Process in Physical Education and Sports, (I 1), Alexandria, Egypt: Knowledge Facility in Alexandria.

Adams، M. (2010). BTEC Level 3 National Sport. (Performance and Excellence) Student Book.

Al-Ahdal, Ahmad Mohammed (2006). The impact of a training program to develop offensive planning behavior of the young football players. Unpublished PhD thesis, Alexandria University.

Ali, Adel Fadel (2005), Tactical Knowledge and its Relationship to the Tactical Behavior in Fencing game, Journal of Physical Education, University of Baghdad, Vol. 14: 191-200.

Al-Faqih, Mastour Ali (2008). Proposed training program for the development of planning behavior by using the computer for football players. Unpublished PhD thesis, Helwan University, Egypt.

Al-Hayek, Sadeq and Al-Dmoor, Bilal Awad (2010), the Effect of Teaching Tactical Aspects in Football Using Computer on Tactical Thinking and Decision Making among Students of the Faculty of Sport Sciences at Mutah University, MA Thesis, Mutah University.

Al-Hawari, Maryam (2011). Emotional Intelligence and its Relationship to Decision Making among Mu'tah University Students, Unpublished Master Thesis, Mu'tah University, Karak, Jordan. 
Al-Qaraan, Abdul Jalil Abdulnabi (2003). The Effect of an Educational Program Based on "Sternberg's Three-Way Theory for Improving Decision-Making in First-Grade Students (Literary / Scientific) Unpublished PhD thesis, Amman Arab University for Graduate Studies, Amman, Jordan.

Al-Saleh, Majed Salim (2011), the impact of an educational program using computer technology to develop basic skills and some physical qualities in basketball for the hearing impaired. PhD. Published thesis, University of Jordan, Hashemite Kingdom of Jordan.

Al-Waqqad, Mohammad Reza (2003). Modern Football Planning, Dubai, UAE: Dar Al Saada Printing \& Publishing.

Al-Zghoul, Rafi al-Nusair; and Al-Zghoul, Imad Abdul Rahim. (2009) Cognitive Psychology, (i 1), Amman, Jordan: Dar Al Shorouk for Publishing and Distribution.

Barell، j، (1991). Grating our path ways: Taeching Students to Think and Become Self-Directed In Colangelo \& G.A. Davis (Eds) Handbook Of Gifted Education (Pp 252-270) Needham Heights، MA: Allyn and Bacon.

Bishtawi, Muhannad and Khawaja, Ahmed Ibrahim (2005). Principles of Sports Training, Amman, Jordan: Dar Wael.

Dulaimi, Nahida Abd Zaid. (2006) the effect of using computer on learning the skill performance of the overwhelming volleyball transmission, Journal of Physical Education Sciences - University of Babylon. One (3), 82-107.

Hammad, Mufti of Ibrahim. (1998), Modern sports training / planning, application and leadership. (I), Cairo, Egypt: Arab Thought House.

Hamam, Khalid Abdul Rahim, (2004), e learning and computerization of education, the first edition, Amman, Al Dustour Commercial Press.

Haniyeh, Raed Suleiman (2006). The effect of using computer in teaching the skill of passing from top to forward in volleyball for the tenth grade, unpublished master thesis, Yarmouk University, Irbid, Jordan.

Hayek, Sadiq and Khaldi, Hassan. (2006), The ability of the teacher of physical education to make appropriate decisions in some school situations, the fifth international scientific conference, Vol (2): 215-234.

Holt، N. \& Sparkes، A. (2001). An ethnographic study of cohesiveness in a college soccer team over a season. The Sport Psychologist، (15). Pp 237-259. https://doi.org/10.1123/tsp.15.3.237

Khayoun, Yarub and Ali, Adel Fadel (2008). Factors affecting reaction time and decision-making.

Mahmoud, Mohamed Hamida (2005). A training program to develop the ability of tactical thinking of the effectiveness of the tactical attack and the rapid apostate defense of the football player. Unpublished doctoral thesis, Alexandria University, Alexandria, Egypt.

Mohammadi, Mamdouh; Ali, Mohamed (1998). Mental Preparation and Development of Tactical Thinking for Football Players, Cairo, Egypt: Dar Al Fikr Al Arabi.

Morris، Terry. Graydon، jan. (1996). The effect of exercise on the design performance of experienced and inexperienced soccer player. Research quarterly for exercise and sport . American and alliance for health، physical education، recreation and dance. https://doi.org/10.1080/02701367.1996.10607933

Nassif, Ghaith Mahmoud. (2006). Tactical Thinking of Handball Players in Jordan, Master Thesis (Unpublished), Yarmouk University, Irbid, Jordan.

Shaalan, Ibrahim and Abu Al-Majd, Amr. (1996). Foundations of the construction of comprehensive football, (I 1), Cairo: Egypt Academic Library.

Turner، A. Martinek، T. (1995). Teaching for understanding: A model for improving decision making during game play. Quest، Vol. (47), Pp. 44-63. https://doi.org/10.1080/00336297.1995.10484144 


\section{APPENDIX (1)}

Selected models of the program of the tactical aspects used in the study.

Program of tactical aspects of basketball.

Key to using shapes:

\begin{tabular}{|l|l|}
\hline Shape & Interpretation \\
\hline & Defender \\
\hline & Offensive \\
\hline & Ball \\
\hline & Pass path (pass) \\
\hline & Player's path without a ball \\
\hline & Exchange the pass of the ball between two players \\
\hline
\end{tabular}

Form 1.

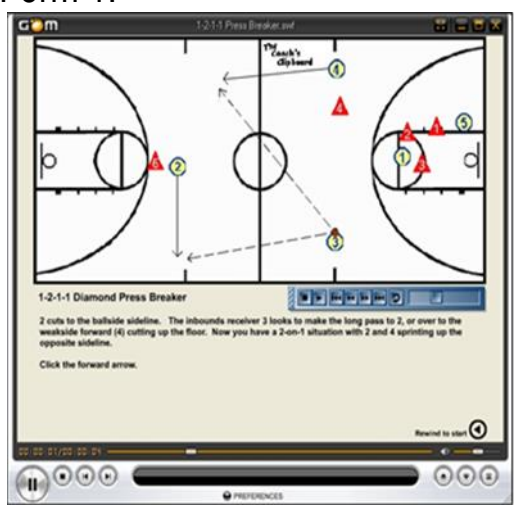

Form 2.

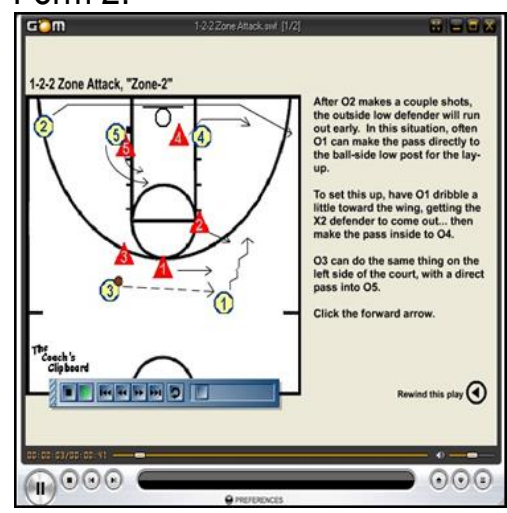

Form 3.

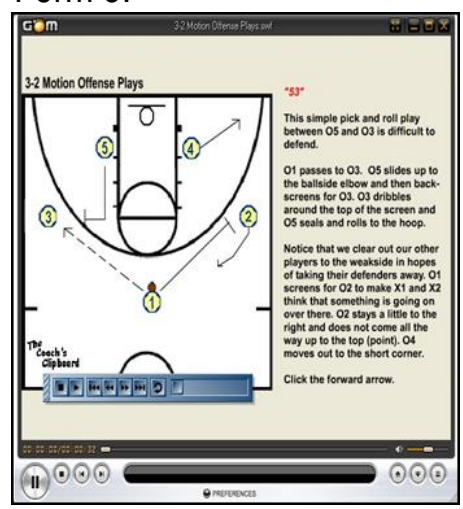

\section{APPENDIX (2)}

A model of the Technical Thinking scale.

Please kindly put a sign ( $\mathrm{x}$ ) on the appropriate option to achieve a goal for each situation according to your point of view as a player and according to the offensive position and your thinking as a player on the field 
Form 1.

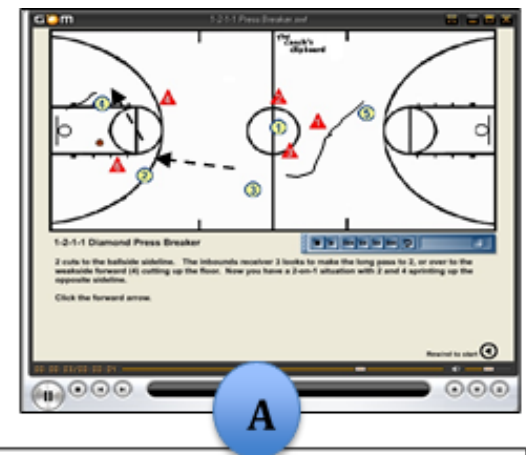

The playmaker (1) passes the ball quickly to the wing player (3) after tricking the defender and then move player (1) to block the wing player on the other side (2) who steps forward to take the place of the playmaker, and then move the player (5) To book the wing player (3) and then open the way for several attempts and possible positions through completing the plan.

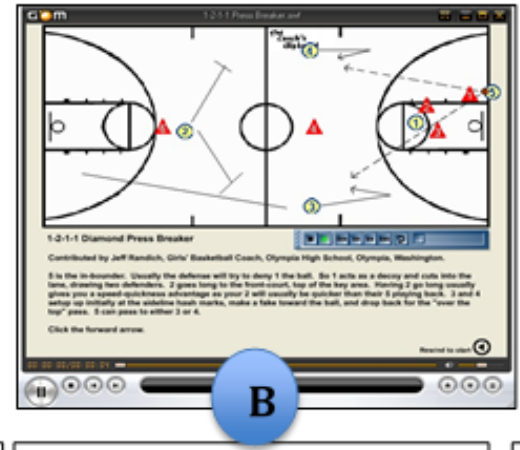

The player (3) quickly passes the ball on the three-point line to the player (1) who steps forward from behind and opens the way for each of the players (5) to the middle or move the players (4) and (2) to the outside of the arch, and free player (3), Complete viewing the plan and consider the possibilities .

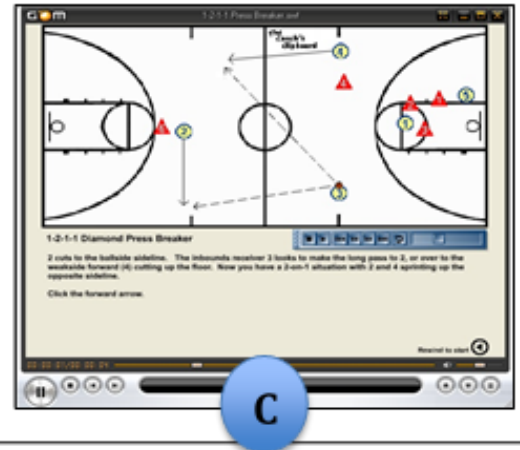

The player (3) passes the ball after receiving the ball and get inside to the half of the court to the player (4) who steps forward from behind or (2) on the border of the three-point area and aiming the ball, who are either penetrating towards the basket or scoring three points.

The video is displayed for the entire plan or with full options depending on the playing position.
Form 2.

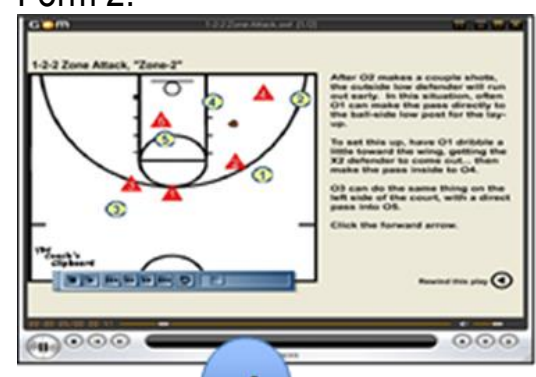

\section{A}

3 Player 3 steps forward and passes the ball to player 2 and passes it to player 4 inside the bottom of the basket.

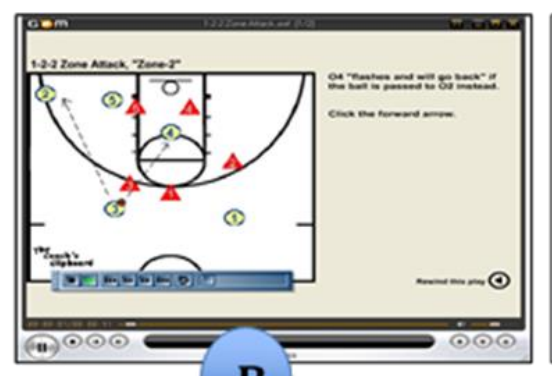

B

2 Players 3 and 4 rip off and return to receive the ball and player 3 runs towards the side of the stadium and player 2 booked the defender and target. On the other hand, passes to the player 4 and target.

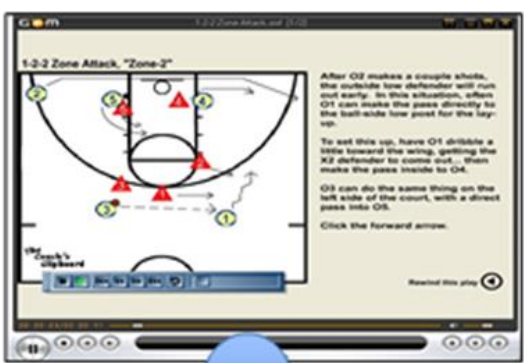

C

1 After the player 3 receives the ball, he passes to 4 with the entry of 3 to pass the ball for him for targeting a triple.

\section{APPENDIX (3)}

The key to correcting the scale of tactical thinking.

\begin{tabular}{|l|l|l|l|l|l|l|l|}
\hline Form Number & Form A & Form B & Form C & Form Number & Form A & Form B & Form C \\
\hline Form 1 & 2 & 1 & 3 & Form 9 & 2 & 3 & 1 \\
\hline Form 2 & 2 & 3 & 1 & Form 10 & 3 & 1 & 2 \\
\hline Form 3 & 2 & 1 & 3 & Form 11 & 1 & 3 & 2 \\
\hline Form 4 & 2 & 3 & 1 & Form 12 & 3 & 2 & 1 \\
\hline Form 5 & 2 & 3 & 1 & Form 13 & 1 & 2 & 3 \\
\hline
\end{tabular}




\begin{tabular}{|l|l|l|l|l|l|l|l|}
\hline Form 6 & 2 & 1 & 3 & Form 14 & 1 & 3 & 2 \\
\hline Form 7 & 3 & 1 & 2 & Form 15 & 1 & 3 & 2 \\
\hline Form 8 & 2 & 1 & 3 & Form 16 & 1 & 2 & 3 \\
\hline
\end{tabular}

\section{APPENDIX (4)}

Decision Making Scale.

My student brother......

Peace be upon you and god's mercy and blessings:

The researcher conducts a study entitled:

(THE IMPACT OF PROGRAMMED E-LEARNING OF THE TACTICAL ASPECTS ON THE LEVEL OF TACTICAL THINKING AND DECISION-MAKING FOR BASKETBALL COURSE STUDENTS)

Please kindly put a reference $(\mathrm{x})$ on the appropriate option to achieve a goal for each of the positions according to your point of view as a player and according to the offensive position and your thinking as a player in the stadium.

Thank you for your cooperation.

Researcher: Dr. MAJED El-SALEH

Personal data:

\begin{tabular}{|l|l|}
\hline Name & \\
\hline Age & \\
\hline length & \\
\hline Weight & \\
\hline School year & Yes \\
\hline Are you a player? & No \\
\hline
\end{tabular}

Please kindly answer the scale paragraphs by placing an $\mathrm{X}$ in the appropriate box from your point. 